Revue de l'Institut des langues et cultures

d'Europe, Amérique, Afrique, Asie et Australie

$41 \mid 2020$

Escrituras nómadas en el mundo hispánico contemporáneo

\title{
De tuiteratura: una aproximación (y algunas reflexiones desde la tuiteratura mexicana)
}

On Twitterature: an Approach

À propos de la twittérature : une approche

Paulo A. Gatica Cote

\section{OpenEdition}

\section{Journals}

Edición electrónica

URL: http://journals.openedition.org/ilcea/11357

DOI: 10.4000/ilcea.11357

ISSN: 2101-0609

Editor

UGA Éditions/Université Grenoble Alpes

Edición impresa

ISBN: 978-2-37747-224-6

ISSN: $1639-6073$

Referencia electrónica

Paulo A. Gatica Cote, «De tuiteratura: una aproximación (y algunas reflexiones desde la tuiteratura mexicana)», ILCEA [En línea], 41 | 2020, Publicado el 03 noviembre 2020, consultado el 02 febrero 2021. URL: http://journals.openedition.org/ilcea/11357 ; DOI: https://doi.org/10.4000/ilcea.11357

Este documento fue generado automáticamente el 2 febrero 2021

(C) ILCEA 


\title{
De tuiteratura: una aproximación (y algunas reflexiones desde la tuiteratura mexicana) ${ }^{1}$
}

\author{
On Twitterature: an Approach \\ À propos de la twittérature : une approche
}

Paulo A. Gatica Cote

\section{NOTA DEL AUTOR}

\section{Bonus track}

Esto es un texto pensado para su publicación en 2020. Dos años: una vida. Twitter nació bajo una pregunta que casi nadie recuerda. En 2017, mientras escribía y pensaba sobre estos temas para mi tesis doctoral, el número mágico de los 140 caracteres fue duplicado. No hace mucho, apenas un año, se empezaron a conectar varios tuits «para proporcionar más contexto, una actualización o para ampliar una opinión» (palabra de Twitter, Inc). Así pues, he abierto un hilo, que, realmente, hoy, treinta de septiembre de 2019, estoy cerrando para enviar una versión completa de este trabajo para el monográfico «Escrituras nómadas en la literatura contemporánea en lengua española» propuesto por la revista ILCEA. De todos modos, ¿cómo detener los infinitos flujos de imágenes, reflexiones, vídeos, chistes, gifs o memes? O mejor formulado: ¿cómo se puede cartografiar lo efímero, capturar un instante o un tuit destinado a perderse en la corriente de timelines en el tiempo que se tarda en leer las conclusiones? ¿Qué será de la tuiteratura cuando se publique el número? Quo vadis.

«Las convenciones del arte son alteradas por las obras de arte.» Sol le Witt 


\section{Introducción: ¿cómo (se) respira (en) Twitter?}

1 El conocido ensayo de Gabriel Zaid Los demasiados libros comienza con esta reflexión que alerta de la inflación autorial en un mercado cada vez más saturado por la multiplicación de la oferta: «los libros se multiplican en proporción geométrica. Los lectores, en proporción aritmética. De no frenarse la pasión de publicar, vamos hacia un mundo con más autores que lectores» (2010: 9). El ecosistema del libro ya había «sufrido» anteriormente desequilibrios tras la generalización de la imprenta de tipos móviles o la progresiva alfabetización de la sociedad. Ahora bien, dichos reordenamientos carecían de la inmediatez y la influencia de un proceso que trasciende el mal definido impacto tecnológico y configura un nuevo campo de desarrollo para las prácticas creativas, críticas y editoriales.

2 En un modelo cultural librocéntrico, la comunicación literaria se presenta altamente codificada en torno al libro entendido como producto u objeto físico, cuya producción, venta y disfrute están regulados por el mercado. No obstante, el valor no es indiferente a criterios supuestamente estéticos, ya que a lo largo del proceso la obra ha de pasar determinados filtros de legitimación encarnados por la figura del «experto» en sus diferentes formas: crítico, agente literario o comité editorial. En este sentido, existe un referente institucional que sanciona la relevancia o, directamente, prescribe más que diagnostica las tendencias que han de disputarse o compartir la hegemonía. En cambio, un medio que confiere idéntica visibilidad a cada una de las expresiones allí recogidas sugiere varios interrogantes: ¿cómo se crea el valor?, ¿Qué tipos de mecanismos de reconocimiento operan para distinguir la praxis artística de la praxis comunicativa?, ¿Cómo y dónde se archivan las prácticas legitimadas?

3 No es este el lugar para explorar por completo estas líneas, aunque sí hay que partir de una idea clave para comprender el fenómeno analizado: la lucha por la visibilidad. Precisamente, la metáfora de la respiración ha de leerse desde esta premisa. Aun a riesgo de menoscabar el contenido conceptual, la condición oceánica de Twitter remite a la imagen de una extensión inconmensurable de agua sometida a fuerzas o corrientes bajo la superficie: millones de tuits, hashtags, menciones y gifs que se suceden sin solución de continuidad y apenas ocupan escasos segundos en el timeline. En definitiva, cada tuit supone un pequeño espacio de 280 caracteres en la pantalla destinado a ser arrastrado por la corriente del medio. Como concluye Luelmo ingeniosamente en un metatuit: «Tuiter es una epidemia de letrosos» (2016).

4 En este contexto de sobreabundancia textual los usuarios deben aprender a respirar bajo el agua para no acabar sofocados ante la imposibilidad de fijar la temporalidad del medio. A simple vista, la «respiración» cumple con al menos dos funciones: una creativa y otra hermenéutica. Por un lado, el prosumidor desarrolla estrategias para «sacar la cabeza», generar visibilidad y valor añadido tanto por los contenidos propios $-\mathrm{y}$, por supuesto, selecciones, retuiteos y recomendaciones- como por la calidad de sus círculos; por otro, el usuario se familiariza con los códigos del medio de tal forma que le permite detectar la relevancia individual y de las posibles trayectorias entre los signos.

5 Desde este punto de vista, la provisionalidad y la percepción homogénea confieren -en teoría - a cada tuit idéntico final y preeminencia en el magma comunicacional. Sin embargo, la visibilidad no consiste únicamente en la espacialización de las prácticas en entornos de legitimación institucional como el museo o los fondos de librerías y editoriales, en los que el visitante sabe que «accede» a un lugar-otro destinado al 
consumo cultural, sino que esta distinción se ha interiorizado y se manifiesta como un deseo de reconocimiento basado en la reputación; es decir, en el valor que la comunidad confiere a cada aportación ${ }^{2}$.

6 En consecuencia, la visibilización de los contenidos en las redes sociales está muy relacionada con la producción-percepción de una identidad -entiéndase perfil atractivo-, ya sea por el alto grado de seguimiento/(re)conocimiento, por su actividad en nodos o redes consideradas valiosas, o por la atracción de los tuits alojados. En el caso concreto de la creación en Twitter, la presencia de un «nombre-marca»o «marcas yo» (Escandell, 2014: 109) es una de las principales vías de adquisición de reconocimiento ${ }^{3}$. Si el yo «autorial» disfruta de suficiente capital simbólico, resultará más factible que sus contenidos cuenten con un alto nivel de atención; de esta manera, los mensajes serán leídos como un hecho diferenciado del resto desde su posicionamiento en el sistema literario. La autoridad no se cifra únicamente en el «capital de consagración» acumulado (Bourdieu, 1995: 224) en la esfera del libro, pues, según Bauman, «la autoridad sirve para engrosar las filas de los seguidores, pero en un mundo con objetivos inciertos y crónicamente indeterminados, el número de seguidores es lo que define $-\mathrm{y}$ es- la autoridad» (2009: 73).

De todas formas, no se puede asumir que todos los contenidos son «consumidos» al igual que no todos los enlaces son activados; es más, habría que confrontar una cierta visión romántica del lector-explorador de hipertextos con la figura más prosaica del seguidor, quien, difícilmente, permanece atento a cada actualización o consulta del timeline que se prolongue por más de algunos minutos. Por esta razón, ante las habituales maniobras de scrolling, skimming o scanning, condicionadas por su puesta en pantalla y por la presentación en la red social, el prosumidor se afana en concentrar / encontrar una serie de «ideas fuerza» (Raphael, 2011: 48) que susciten el interés. Lógicamente, no se trataría aquí de detener el flujo semiótico, sino de provocar un encauzamiento alternativo del timeline. Como explica Wirth:

Los enlaces solo se vuelven informativos en la medida en que implican una estructura específica de relevancia, o bien porque el lector reconoce la irrelevancia específica de un enlace [...]. La estructura de los enlaces es una pista, la huella de una estrategia discursiva (1998: 63).

De lo anterior se colige la dificultad a la que se enfrenta el cibernauta a la hora de establecer balizas o puntos de referencia: su notoria descontextualización respecto al sistema literario y a los propios mensajes de Twitter. La comunicación en la web social se muestra más proclive a los intercambios sincrónicos, efímeros y no planificados, «con límites de extensión o incomodidades contextuales» (Cassany, 2012: 76). Paradójicamente, este tipo de escrituras veloces, calificadas de superficiales e improvisadas, ha propiciado la recuperación de formas y géneros breves que tienden a condensar y expandir su carga semántica -en pocas palabras, aumentar el tiempo necesario para su decodificación - como la minificción, el aforismo o el haiku (Tascón \& Abad, 2011: 98). Al respecto, el Slow Twitter supone un tipo de práctica signada por la profundidad, la inteligencia, el humor y la precisión (Orihuela, 2011: 104).

\section{De tuiteratura}

9 Twitter carece de la estabilidad institucional y tranquilizadora del libro. Frente a los valores de permanencia e inteligibilidad del soporte analógico, la red social posee cierta 
condición de espacio «cero» o sin marcar. Los modelos exportados a la red social son fusionados y reinterpretados a partir de las coordenadas tecnológicas; sin embargo, esta influencia se materializa por más vías que la mera «adaptación» a un nuevo ambiente. En el caso de Twitter, surgen nuevas formas y actualizaciones de géneros literarios «consagrados» como las minificciones serializadas o algunos proyectos colaborativos. Como se verá, "escribir consiste, esencialmente, en concebir engramaciones de modelos y, por lo tanto, "posibilidades" de textos» (Balpe, 2012: 157). Las mediaciones textovisuales del libro y de las redes sociales difieren, sobre todo, en esa codificación que posee el libro e, incluso, en la misma idea de texto asociado a dicho soporte.

La creación literaria y el libro han formado un tándem tan natural y aceptado que tienden a obviarse los factores «artificiales» que intervienen en dicha pareja. Eso sí, admitir la existencia de su sustrato tecnológico implica aceptar la posibilidad de modificación, influencia o reemplazo por el advenimiento de un contexto mediático distinto. Evidentemente, este proceso no ha de ser visto como un cambio de paradigma o brecha en una cronología lineal; más bien, se advierte la imbricación y convivencia de dos sistemas de comunicación: analógico y digital.

De modo ejemplar, la comunidad online ha demostrado una asombrosa capacidad de aprovechamiento del paisaje mediático 2.0, presidido, sobre todo, por redes sociales como Facebook, Instagram o Twitter. Asimismo, es de rigor reconocer que la web acoge una miríada de bitácoras, foros y perfiles que facilitan la pulsión expresiva de la «multitud conectada». En este ambiente de fiebre extimista, libre de los filtros tradicionales que limitan la autopublicación, se va a incentivar el cultivo de formas breves por la conjunción, principalmente, de dos factores: por un lado, las propias características del medio imponen un número de caracteres limitados -280 en el caso de Twitter-, así como una producción y recepción casi sincrónicas y sin mediación institucional o mercantil; por otro, se percibe en el usuario una confusión, en principio, de índole estética, pero con terribles efectos pragmáticos: brevedad = facilidad = mayor rendimiento productivo. En concreto, esta ecuación se va a traducir en una traslación del par celebridad / visibilidad al ámbito restringido de la creación en el ciberespacio (Gatica, 2017: 64-65). En la red social, más allá de puntuales comportamientos «pasivos», se promueve y recompensa la actividad escrilectora que, como explica Orihuela, «no está únicamente delimitada por la calidad de sus redes, sino también por la calidad y la frecuencia de sus propias contribuciones, en la medida en que generan reacciones y respuestas que acaban reconfigurando su propio timeline» (2011: 40).

De todas formas, si bien es cierto que la mayor parte del «tráfico creativo» en la red social puede catalogarse como «selfie artístico» (Aparicio, 2015: 207), enunciados comunicativos que buscan alcanzar un valor adicional por su viralización, es posible rescatar de la inmensa corriente de tuits un conjunto de prácticas que trascienden el ámbito de los contenidos «profanos» (Groys, 2005: 76) o no legitimados ${ }^{4}$. Aun así, habría que buscar ese nexo entre microtextos que cuentan con el respaldo de una tradición literaria y un alto nivel de reconocimiento, y la tuiteratura, neologismo que remite a la red social corporativa Twitter fundada en 2006. Si un evento como el Super Bowl produce millones de tuits ${ }^{5} \mathrm{y}$ miles de millones de visitas durante el partido ${ }^{6}$, ¿cómo se puede establecer un vínculo entre esferas tan dispares?

Reproduzco por su interés la respuesta de Carla Raguseo: 
¿Cuál es la relación existente entre la Minificción y Twitter? ¿Existe la denominada «Tuiteratura»?

Twitter, tanto como red social o como plataforma de microblogging, implica otras formas de producción, recepción y circulación de la palabra. La primera relación que encuentro es la de la interfaz de escritura que en sí misma sugiere la publicación de un texto muy breve, limitado a 140 caracteres, y una presentación fragmentada en un flujo de información. Asimismo, la publicación en este tipo de entorno requiere de ciertas estrategias como el uso de «hashtags» o "etiquetas» para poder filtrar y canalizar su circulación en las redes y poder establecer conexiones.

No todos los intentos microficcionales en Twitter tienen, seguramente, un valor literario. Supongo que la existencia y los alcances de la «Tuiteratura» deberá ser analizada desde los círculos de legitimación de la literatura (Plesiosaurio, 2014: 154-155).

De la declaración de Raguseo merece la pena subrayar algunas ideas. A su entender, se trataría de un medio signado por la «producción, recepción y circulación de la palabra», la brevedad y la presencia fundamental de elementos paratextuales como el hashtag para localizar y clasificar los tuits. En este sentido, la especialista «eleva» la responsabilidad de su rescate a las instancias de legitimación «de la literatura». A esto último se podría añadir «sean cuales sean»o, al menos, podría preguntarse por sus competencias en materia digital.

Por otra parte, además del determinante cuantitativo, Rike Bolte se muestra certera al establecer una serie de paralelismos ente lo que denomina «características micromediáticas» y la microficción. Desde este punto de vista, el factor espacial resulta menos decisivo, ya que lo «micromediático literario» posee unos rasgos que ofrecerían un retrato más fidedigno de las particularidades de este tipo de formas; a saber:

16 - Su extensión interna y la función operativa in medias res lo aproximan -inclusive lo impulsan - a su objeto de narración como también a su destinatario (> cercanía, instantaneidad, interruptibilidad, intervencionalidad);

- Su reducida extensión lo hace ser rápidamente captable para la primera clasificación (visual), precedente a la lectura (> óptima tasa de reconocimiento);

- Su formato es apto para la conectividad: dispara una economía del enlace y de la circulación y lo pone a un nivel alto de complicidad intertextual (> secuencialidad, accesibilidad, condensación de intereses) [2015: 258-259].

17 Siguiendo a Bolte, más allá de la validez de la comparativa, tanto los micromedios como las minificciones presentan una dinámica y unos objetivos comunes: la consecución de microimpactos, caracterizados por:

18 1. La cercanía, la conectividad, la circulación (en términos de espacio).

2. La instantaneidad, la interruptibilidad, la secuencialidad (en términos de tiempo).

3. La condensación de intereses, un alto nivel de reconocimiento y accesibilidad, la intervencionalidad, bottom up (en términos de funcionamiento y efecto) [2015: 256].

De acuerdo con esta clasificación, el microimpacto sobreviene en la confluencia de estas tres líneas; con todo, se advierte un cierto escorzo teórico que igualaría en el plano formal particularidades provenientes de diferentes sistemas. Bolte se apoya en Downing (2010) para resaltar que los dos aspectos fundamentales de los micromedios son «el uso de la expresión comprimida y la conexión, y con ello la producción de la “comunidad horizontal"» (2015: 256). Sin embargo, la consideración conectiva, 
instantánea, accesible, secuencial o interactiva, si bien es aceptable en la red, difícilmente se podría extender a la ecología mediática del libro. Esta visión, aunque muy sugestiva, denota una cierta adhesión al textualismo postestructuralista que, en este caso, omite toda la realidad micromediática / minificcional analógica.

Claramente, la aportación de Bolte resulta muy valiosa para comprender el «funcionamiento» de la minificción en el panorama micromediático digital. Como explica la especialista alemana, la microficcción "está experimentando un updating digital» (2015: 254), que la aproxima a prácticas «micropolíticas» de producción de visibilidad basadas en el desocultamiento de «lo que yace en las profundidades, en las áreas que no tienen cobertura macromediática» (2015: 257). Asimismo, y regresando a algunas de las ideas ya planteadas en este artículo, se podría afirmar que las formas breves mantienen un delicado equilibrio en el ciberespacio que resume perfectamente la vocación, el temor y el destino de la tuiteratura: o la invisibilización por los grandes flujos mediaticos o el microimpacto viralizado.

\section{Algunas reflexiones desde la tuiteratura mexicana}

21 En un primer momento, llama la atención que algunos de los planteamientos más sesudos sobre la tuiteratura provengan de sus cultivadores. Estas incursiones reflejarían el estado de tentativa o de transición mediática: de la escritura en papel a la escritura digital. No obstante, habría que matizar con Wirth que la noción clásica de literatura es deudora de su soporte fetiche -el libro impreso-; de ahí que las textualidades digitales - entre ellas, la tuiteratura- se vean redefinidas no por su materialización en papel, sino por sus «nuevas formas de escritura» (Chimal, 2014: 158) y por unos protocolos de consumo y distribución diferentes.

22 El mexicano Mauricio Montiel Figueiras $(1968)^{7}$, padre literario de $E l$ hombre de tweed ${ }^{8}$, uno de los proyectos narrativos más ambiciosos de la red, publicó en Twitter una poética de la «tuitficción» que sintetiza en cinco «flechazos»" las principales problemáticas a las que se enfrenta el creador en este medio:

23 1. La tuitficción no tiene que ver con cortar en pequeñas partes un relato escrito convencionalmente. Implica concisión y precisión.

2. La tuitficción se puede dividir en dos grandes grupos: historias escritas en 140 caracteres y narrativas episódicas relatadas en tuits.

3. La tuitficción puede demorarse días, semanas e incluso meses en la construcción de una historia que entra y sale del timeline.

4. La tuitficción apela a la capacidad de asombro del lector que es capaz de dejarse deslumbrar por una serie de relámpagos narrativos.

5. La tuitficción cumple con los principios canónicos del relato (inicio, nudo, desenlace) en un espacio reducido. Magia de la brevedad (Saavedra, 2014: 71-72).

Sin entrar a valorar la pertinencia de la palabra «(tuit)ficción» en vez de tuiteratura, los dos primeros puntos indican con claridad la necesidad de una escritura consciente de la «técnica» que la constituye y mediatiza: concisa, precisa y adaptada - no traducida- a la limitación de caracteres. Precisamente, esta "puesta en obra» de la palabra o «engramación» implica, según Jean-Pierre Balpe, «la adaptación de una voluntad o de una búsqueda de expresión en las obligaciones técnicas del medio utilizado para su mediación» (2012: 149). Eso sí, frente a la fija y estable del libro, la mediación digital ejercida a través de las pantallas promueve modalidades alternativas, por lo que habría 
que hablar de potenciales engramaciones que exploran, más que el núcleo artístico del texto mediatizado, las «ambigüedades» generadas por su puesta en pantalla (Balpe, 2012: 157).

Una muestra notable de esta ambigüedad inherente a las engramaciones digitales se localiza en el tercer punto de la poética de Mauricio Montiel. Para el narrador jalisciense, la tuitficción convive indiferenciada en el timeline junto a otro tipo de contenidos; de hecho, resultaría imposible determinar la especificidad artísticoliteraria de estas creaciones sin la presencia de otras marcas extratextuales proporcionadas por Twitter. Como ya argumenté (Gatica, 2015), Twitter es un espacio carente de índices genéricos reconocibles en formato libro, pero existen formas de etiquetado que facilitan la interpretación. Aparte de las consabidas opciones de responder, retuitear o hipervincular archivos o direcciones web, la red social posibilita la adición de tags, un tipo de metadato que permite el filtrado y recuperación de los contenidos etiquetados; así, gracias a la indexación, se puede salvar relativamente de la entropía del medio y, al mismo tiempo, crear formas de presentización y articulación de los tuits encadenados: en otras palabras, se predispone una narrativa.

Por otra parte, el hashtag puede ofrecer una referencia «libresca», una clave interpretativa a partir de la cual el lector familiarizado con los códigos pueda situar el tuit dentro de una serie genérica conocida. Las etiquetas \#aforismos, \#cuentuitos, \#palíndromos o \#poetuits van a orientar la lectura dentro de un «horizonte genérico» (Schaeffer, 2006: 104) que, evidentemente, puede $-\mathrm{o}$ no- manipularse. Con todo, Montiel obvia en esta materia un elemento clave que complementa la «fijación» textual mediante procedimientos de etiquetado: el enunciador. Como argumenta Escandell, el autor afronta «un entorno cambiante, que está en un perpetuo estado de mutación y traslación [...]. Por tanto, el camino de la creación del espacio y la identidad propios será más complejo para el escritor que busque establecer una entidad creativa en el espacio virtual» (2014: 24).

Acerca de esta cuestión no debe despreciarse la fuerza de la firma ni del archivo, puesto que el capital simbólico acumulado en la realidad analógica siempre permea. La autoría, respaldada por la crítica y el mercado, transfiere su «valor» al perfil digital, aunque el uso quede, en general, relegado a la autopromoción y publicidad de obras y eventos por medios de mayor alcance que las revistas culturales o las páginas de prensa. Adicionalmente, esta legitimación offline puede verse refrendada por los internautas, con quienes mantendrá - en una tesitura ideal- una intensa y productiva interacción; o también puede darse el fenómeno inverso: el reconocimiento masivo y el estatus de celebridad online promueven la «exaltación» de su auctoritas y la posterior entrada en el archivo institucional.

Finalmente, las dos últimas apreciaciones de Mauricio Montiel se centran en la dimensión reducida y en la narratividad. En particular, el cuarto punto juega con las ideas esbozadas acerca de la instantaneidad y condensación del microimpacto; sin embargo, el «relámpago narrativo» y el «asombro», unidos en su factura, competen a ámbitos diferenciados; respectivamente, al ámbito de la construcción y de su recepción. La primera idea se relaciona con la brevedad en un sentido que no tiene solo que ver con la dimensión cuantitativa. Tal como afirma Lagmanovich en varios de sus trabajos, habría que distinguir lo conciso de lo breve (2009: 90), ya que la concisión apela justamente a esa condensación o, en términos de Julio Peñate, a la «lógica del máximo de densidad» (2016: 31). Por su parte, el asombro es consecuencia de una estrategia 
textual que juega con esta lógica y con el citado «efecto de lectura» en un doble sentido: manipulación genérica y manipulación -mediática- del marco de inscripción discursivo.

De un modo similar a la poética de la tuitficción arriba esbozada, el narrador Alberto Chimal (1970) ${ }^{10}$ adopta un enfoque más general que el de Montiel para caracterizar la eXcritura -experimentación + escritura- en Twitter. En su opinión, esta práctica cuestiona pilares básicos de la literatura en libro como la autoría individual, la comunicación unidireccional (creador --> obra --> lector), la taxonomía de géneros literarios o el aura de la obra de arte literaria; o dicho a la inversa, la tuiteratura, aparte de su brevedad esencial, supone la exploración creativa de las siguientes áreas:

1. La escritura y la lectura comunales.

2. La interacción instantánea y diversa.

3. La mutación de géneros preexistentes.

4. La aparición de prácticas nuevas.

5. La erosión de los conceptos del texto definitivo y de la permanencia (2014: 158-160).

31 Se percibe en el listado dos ejes predominantes de actuación, según se dirija la reflexión a las particularidades del medio (1, 2 y 5) o a los frutos tuiterarios (3 y 4). Empezando por el final, Chimal realiza un nuevo deslinde entre las actualizaciones del repertorio genérico -básicamente, su recontextualización-y los géneros tuiterarios per se. En el primer caso, el escritor toluqueño se refiere a la adaptación a un entorno digital de géneros como la minificción o el aforismo que, durante el proceso, conservarían una apariencia reconocible $\mathrm{y}$, al mismo tiempo, adquirirían valores mediáticos como la posibilidad de serialización o el etiquetado. En cambio, las prácticas nuevas serían «géneros sin precedentes» o inclasificables, "pues los textos que engendran se crean muchas veces sin plan ni organización, e invariablemente no permanecen ni forman, por tanto, un corpus que luego puede ser recuperado» (Chimal, 2014: 159).

No obstante, me parece que esta distinción, por muy sutil que sea, enreda más que aclara el supuesto, porque ambas realizaciones, si son consideradas tuiterarias, ya deberían mostrar la relación simbiótica de la creación con la red social. La separación podría llevar a equívoco e inspirar tanto una lectura digitalizada de los textos como un peligroso doblete, que asocia la "preexistencia» al medio analógico y la novedad al digital. Además, como la genología se ha encargado de probar, los géneros literarios nunca «son» ni devienen entidades «puras», sino que conforman espacios en continua hibridación que subvierten cualquier noción ontológico-esencialista de la pertenencia. En definitiva, el matiz clave residirá más en la consideración tuiteraria o literaria de las prácticas que en su supuesta originalidad.

33 En la descripción de Chimal, los rasgos 1, 2 y 5 podrían extrapolarse al espectro completo de la creación digital, aunque con algunas precisiones. Ciertamente, se trata de una escritura socializada, abierta a la participación y a la mirada evaluadora de la comunidad; de ahí que su concepción de Twitter como «laboratorio» público se justifique por ese cambio de rol del receptor, quien se convierte en interlocutor directo con la obra, con el propio creador y con sus redes de seguidores. En palabras del autor: «Twitter sirve para intentar y equivocarse, para lanzar versiones diversas de una idea o argumento a posibles lectores, para interactuar con ellos y modificar o añadir o descartar» (2011). concepción «igualadora» del ciberespacio. No todas las aportaciones «valen» lo mismo, 
lo que, en este contexto, quiere decir que sigue existiendo la capacidad de elección. Como explica Chimal: «todos somos -o podemos ser- curadores de nuestras propias antologías virtuales» (2014: 158); o sea, detrás de cada contribución, de cada like o retuit, existe una «voluntad» o suma de voluntades - humana o maquínica- que, en última instancia, decide en qué conversación quiere tomar parte y con qué tipo de círculos quiere relacionarse ${ }^{11}$.

En efecto, la web social dispone espacios de intervención comunitaria -cuentas y foros especializados, hashtags o eventos- que facilitan la circulación, el feedback y las aportaciones de una red de usuarios «interesados»; de ahí que los proyectos de creación colectiva gocen de tanto predicamento en Twitter. Por ejemplo, la cuenta LossLit (@LossLit), cocreada por Kit Caless y Aki Schilz y su cuenta hermana en español, gestionada por Mauricio Montiel y Miguel Ángel Díaz Monges, LitPerdida (@LitPerdida), acogen y curan sesiones públicas de escritura bajo el hashtag \#LossLit/ \#LitPerdida en las que se explora la sensación de pérdida en cualquier ámbito. Sirva de ejemplo las siguientes contribuciones de El hombre de tweed a @LitPerdida:

[Tengo una enorme colección de llamadas perdidas en mi teléfono celular. Cada una responde a un número que ya no existe. \#LitPerdida] (2016a).

***

[El anciano localizó la carta que había perdido años atrás. Su contenido se reducía a una sola frase: "Lárgate de mi vida." \#LitPerdida] (2016b).

***

[En el centro del laberinto el Minotauro oye los pasos perdidos de Teseo. Sonríe. Su hermana Ariadna ha probado su amor por él. \#LitPerdida] (2016c).

***

[El hijo perdido regresa al cabo de diez años de ausencia. Llama a la puerta de sus padres. Abre un joven muy parecido a él. \#LitPerdida] (2016d).

Tras esta breve disquisición, todavía queda por concluir si se puede hablar con propiedad de una tuiteratura o si, en cambio, habría que adjetivar o complementar de algún modo el sustantivo literatura. De nuevo, no resulta factible establecer una categoría lo suficientemente «elástica» para englobar todas las interacciones, aunque sí se ha recurrido a dos métodos para separar los tuits literarios de la mera conversación. Por un lado, la poética de Alberto Chimal representaría una posición de corte casi kantiano, que interroga directamente a la «tuiteridad» inmanente de estos textos. El escritor mexicano considera que se puede llamar tuiteratura «a toda escritura con aspiraciones o efectos artísticos que se realice y se difunda -de modo totalmente independiente de la letra impresa- en esa red social» (2014: 158). La teoría del arte y la crítica literaria ya desenmascararon la falacia intencional. Por otro, hay posturas que abogan por la comprensión de las circunstancias que influyen en su «literaturización» o, mejor dicho, «tuiteraturización». En este sentido, Escandell diferencia la literatura en Twitter de la tuiteratura, puesto que

una tuiteratura debe, para ser tal, integrar los recursos principales de la red social: vocativos mediante arroba, clasificación dinámica por hashtags y restricción de caracteres; solo así es posible la relación simbiótica entre la esfera de creación literaria y la esfera de Twitter. De lo contrario, estamos ante una simple relación parasitaria en la que la microliteratura se trasvasa de la hoja a Twitter como medio de difusión, pero no como herramienta determinante en el proceso creativo ni en la idiosincrasia de los textos creados (2014: 246-247).

37 En efecto, coincido en la necesidad de reservar la palabra «tuiteratura» para sus usos «simbióticos» frente a los usos «parasitarios» de la red, que cumplirían con una función equivalente a un tablón de anuncios $u$ hoja en blanco -teóricamente abierta a escala 
global- en los que publicar formas microtextuales. Pese a que predomina el segundo tipo de conducta, los creadores siguen demostrando un tremendo ingenio y vitalidad a la hora de apropiarse y explotar las facultades expresivas de las redes sociales. Como subrayan con elocuencia Tascón y Abad: «Twitter es el mayor juego de palabras que ha existido jamás. Es el gimnasio de la mente y de la escritura, en el que la ortografía y la sintaxis son parte de las disciplinas con las que nos entrenamos cada día» (2011: 119).

\section{Conclusión: tuiteratura, ¿y ahora qué?}

Un tuit es básicamente una extensión, un espacio hiperbreve no constreñido a usos artístico-literarios convencionalizados (Gatica, 2014). El tuit, como sentencia Alberto Chimal, no es un género literario (2014: 158); por eso, más que coartar la creación, el límite del tuit ejerce de estímulo para la práctica de géneros como el microrrelato o el aforismo, que tienen en la condensación y en la brevedad sus principales características. Además, la práctica de la brevedad en las redes sociales ha sometido una actividad comunicativa a continuas evaluaciones y reevaluaciones comunitarias de la literariedad / tuiteraturiedad de los contenidos. A través de la visibilización y reconocimiento de los pares, se catalizaría un proceso de estetización de índole ejemplarizante o «aurificadora». No obstante, quedaría pendiente de un análisis más profundo el motivo de ese valor añadido que los usuarios conceden a determinadas prácticas en el ciberespacio, aunque propongo cinco ejes o premisas para la reflexión:

1. Cada interrogante debería ser planteado en función del tipo de comunidad de usuarios, pues no existe un comportamiento único en redes sociales ni un acceso absolutamente libre y total a la web.

2. No hay que absolutizar el comportamiento del usuario «con inquietudes» que realiza un consumo cultural. Los intercambios adscribibles al campo literario representan un porcentaje insignificante de las comunicaciones en Twitter.

3. La velocidad del medio condiciona el tiempo dedicado a la lectura; por consiguiente, la temporalidad se convierte en el campo de batalla: o el tuit es capaz de ofrecer una resistencia efectiva y ralentiza el flujo -atención / atracción- o el tuit es arrastrado por la corriente y queda subsumido bajo otros impulsos e intereses con mayor seguimiento.

4. Una correlación: la visibilidad depende del reconocimiento y el reconocimiento de la visibilidad. El nexo se fundamenta en esos «aires de familia» entre contenidos «profanos» y «valorados», en términos de Groys: en la fusión / tensión de / entre ambos espacios (2005: 134).

5. La hipervisibilidad constituye una de las vías principales de valoración y, en cierta forma, refleja la sustitución de la autonomía del arte por la heteronomía estética o la copresencia de diferentes temporalidades y regímenes de identificación (Ranciére, 2002: 38-40). 


\section{BIBLIOGRAFÍA}

APARICIO MAYDEU Javier (2015), La imaginación en la jaula. Razones y estrategias de la creación coartada, Madrid: Cátedra.

BALPE Jean-Pierre (2012), «Literatura digital. Obligaciones y aperturas de la pantalla. (del bolígrafo al ordenador o del libro a la pantalla)», L. Borràs (ed.), Under Construction: Literatures digitals i aproximacions teòriques, Palma de Mallorca: Universitat de les Illes Balears, 149-158. BAUMAN Zygmunt (2009), Modernidad líquida, Buenos Aires: FCE Argentina.

BolTE Rike (2015), «Difícil diminuto: midiendo el impacto de la microficción en el contexto de una tipología general de lo micromediático», O. Ette, D. Ingenschay, F. Schmidt Welle \& F. Valls (eds), MicroBerlín. De minificciones y microrrelatos, Madrid-Frankfurt: Iberoamericana-Vervuert, 249-264. BOURDIEU Pierre (1995), Las reglas del arte. Génesis y estructura del campo literario, Barcelona: Anagrama.

BUGARINI Luis (2012), «Conversación con Mauricio Montiel Figueiras», en línea en Asidero: <https://asideroarchivos.home.blog/2012/08/09/conversacion-con-mauricio-montiel-figueiras/ $>$

CASSANY Daniel (2012), En_línea. Leer y escribir en la red, Barcelona: Anagrama.

CHIMAL Alberto (2011), «Twitter: literatura a trinos», en línea en La pagina de Beto Buzali: <http:// lapaginadebetobuzali.blogspot.com.es/2011/03/twitter-literatura-trinos-por-alberto.html> (8 de de junio de 2013).

CHImal Alberto (2014), «De tuiteratura», Plesiosaurio. Primera revista de ficción breve peruana, 7 , 157-162.

DownING John (2010), «Nanomedios de comunicación», en línea en InCom-UAB: http:// www.portalcomunicacion.com/catunesco/download/ 2010_DOWNING_NANOMEDIOS\%20DE\%20COMUNICACI\%C3\%93N.pdf

ESCANDELL MONTIEL Daniel (2014), Escrituras para el siglo XXI. Literatura y Blogosfera, MadridFrankfurt: Iberoamericana-Vervuert.

GATICA COTE Paulo A. (2014), «Nuevas tradiciones electrónicas y viejas rupturas de vanguardia en la tuiteratura mexicana», Forma breve, 11, 13-27.

GaticA Cote Paulo A. (2015), «Cuando Twitter encontró el aforismo: nuevas inquisiciones en el debate de los géneros literarios», F. Noguerol Jiménez, M. A. Pérez López \& V. Sánchez Aparicio (eds), Letras y Bytes: literatura y nuevas tecnologías, Kassel: Reichenberger, 149-164.

GATICA Cote Paulo A. (2017), «Las trampas de la brevedad: estética del fraude en la minificción hispánica contemporánea», Fix100. Revista hispanoamericana de ficción breve, 6, 57-72.

Groys Boris (2005), Sobre lo nuevo. Ensayo de una economía cultural, Valencia: Pre-Textos.

LAGMANOVICH David (2009), «El microrrelato hispánico: algunas reiteraciones», Iberoamericana. América Latina-España-Portugal, 36, 85-95.

Luelmo Ana (2016), «Tuiter es una epidemia de letrosos» [Tuit], en línea en Twitter: <https:// twitter.com/Bitropica/status/731248196102414336> (13 de mayo de 2016). 
ORIHUELA José Luis (2011), Mundo Twitter. Una guía para comprender y dominar la plataforma que cambió la red, Barcelona: Alienta.

PEÑATE RIVERO Julio (2016), El cuento literario hispánico en el siglo XX. Variaciones teóricas y prácticas creativas, Madrid: Visor.

Plesiosario (2014), «Entrevista a Carla Raguseo. La brevedad en Twitter», Plesiosaurio. Primera revista de ficción breve peruana, 7, 153-156.

RANCIÈRE Jacques (2002), La división de lo sensible. Estética y política, Salamanca: Centro de Arte de Salamanca.

RAPHAEl Pablo (2011), La fábrica del lenguaje, S.A., Barcelona: Anagrama.

SAAVEDRA Naida (2014), «El auge de la twitteratura: tendencias de la microficción y la literatura 2.0», Plesiosaurio. Primera revista de ficción breve peruana, 7, 61-84.

SCHAEFFER Jean-Marie (2006), ¿Qué es un género literario?, Madrid: Akal.

TASCÓN Mario \& MAR Abad (2011), Twittergrafía. El arte de la nueva escritura, Madrid: Los libros de la Catarata.

WIRTH Uwe (1998), «Literatura en internet. O: ¿a quién le importa quién lea?», C. Giannetti (Ed.), Ars telemática: telecomunicación, Internet y Ciberespacio, Barcelona: ACC L’Angelot, 59-70.

ZAID Gabriel (2010), Los demasiados libros, Barcelona: Debolsillo.

\section{NOTAS}

1. Este trabajo forma parte de las actividades del proyecto de investigación «PERFORMA2. Metamorfosis del espectador en el teatro español actual» (PID2019-104402RB-I00) [2020-2023], financiado con una ayuda del Ministerio de Ciencia e Innovación en el marco del Plan Estatal de Investigación Científica y Técnica y de Innovación 2017-2020.

2. Esta escala de valores no es ajena al mundo offline, como se evidencia de los perfiles sin apenas actividad de personajes relevantes que son seguidos por miles de usuarios.

3. Específicamente, Escandell emplea el término para caracterizar los «usos profesionales que resultan monoorientados, pues se someten a intereses superiores, como la potenciación de una faceta concreta del individuo para potenciar su peso digital y construir una imagen de marca propia en internet» (2014: 109).

4. Boris Groys define el espacio profano como el «ámbito que integra todas las cosas que no están incluidas en los archivos [...], extremadamente heterogéneos, porque está constituido por las cosas más diversas y por los más diversos modos de relacionarse con ellas» (2005: 76).

5. < https://blog.twitter.com/2017/how-the-patriots-sb51-victory-conversation-happened-liveon-twitter> (22/02/2017).

6. <https://twitter.com/TwitterData/status/828657324550156288> (22/02/2017).

7. Mauricio Montiel no solo ha cultivado prácticamente todos los géneros -narrativa, ensayo y poesía-, sino que también ejerce como traductor y editor. Entre otras publicaciones, destacan La penumbra inconveniente (2001), La piel insomne (2002), Terra cognita (2007), La brújula hechizada. Algunas coordenadas de la narrativa contemporánea (2009), Paseos sin rumbo. Diálogos entre cine y literatura (2010), Señor Fritos (2011), La mujer de M. (2012), Ciudad tomada (2013) o Los que hablan. Fotorrelatos (2016).

8. Tetralogía novelesca iniciada en 2011 -El hombre de tweed: la ciudad, El hombre de tweed: la isla, El hombre de tweed: la epidemia y La mujer de $M$, único proyecto que todavía sigue activo en Twitter. 
Sin entrar en muchos detalles, salta a la vista la cohesión del trabajo de Montiel, quien dirigía la ficción desde las cuentas de usuario de cada personaje -@Elhombredetweed y @LamujerdeM, aunque la primera se convirtió prácticamente en la cuenta oficial del autor. Esta coincidencia entre cuenta oficial y cuenta del personaje es clave para comprobar la evolución de este proyecto por entregas o, empleando el calificativo del escritor mexicano, «novela de folletuit». Como el propio narrador relata en una entrevista: «fue gracias a la recepción sorpresiva, inesperada, del personaje, que continué escribiendo sobre sus andanzas [...]. Sobre todo en la primera parte, al enviar el tuit tenía una respuesta inmediata de los lectores. Preguntaban, opinaban, se interesaban. Nutrían la propia escritura. Había suspenso. Inclusive hice consultas sobre el destino del personaje» (Bugarini, 2012). No obstante, a pesar de la colaboración con los seguidores, El hombre de tweed es una obra destinada a su publicación en papel (Bugarini, 2012).

9. Utilizo la terminología del propio escritor para introducir las microantologías de citas, aforismos o pensamientos que, con frecuencia, publicaba en la red social bajo ese calificativo: flechazos, balazos, etc.

10. La obra de Chimal siempre se ha sentido cómoda en las distancias cortas del cuento: Gente del mundo (1998), Éstos son los días (2004), La ciudad imaginada (2009), El último explorador (2012), Los atacantes (2015), Manos de lumbre (2019). Aun así, el narrador mexicano ha sabido adaptarse y jugar con la extensión breve -Grey (2006), 83 novelas (2010), El viajero del tiempo (2011), El gato del viajero del tiempo (2014), Historia siniestra (2015)-; con el formato novelesco - Los esclavos (2009) y La torre y el jardín (2012); e, incluso, dio el salto a la novela gráfica: Kustos: Libro 1 (2013) y Kustos: Libro 2 (2014). Esta inclinación hacia la brevedad se vio agudizada por la emergencia de Twitter como plataforma de escritura de textos mínimos. Por ejemplo, dentro de su producción tuiteraria sobresalen 83 novelas (2010), El viajero del tiempo (2011), El gato del viajero del tiempo (2014) o los proyectos para \#TwitterFiction Festival «CiudadX» y «Día común», ambos recogidos y publicados en papel bajo el título Historia siniestra (2015).

11. Por ejemplo, Chimal cuenta con una nutrida comunidad formada por más de cien mil seguidores, tercia en las conversaciones y establece vínculos con otros creadores legitimados o amateurs. Con frecuencia, los grupos de escritores que producen parte de su obra más interesante online se conocen, se leen y, sobre todo, llevan a cabo realizaciones inspiradas por una suerte de poética común. Sin duda, hay una continuidad entre Alberto Chimal y algunos de los más activos usuarios con obra reconocida online y offline como los creadores mexicanos ya citados Mauricio Montiel, Aurelio Asiain, José Luis Zárate, Cristina Rivera Garza o Merlina Acevedo.

\section{RESÚMENES}

La comunidad online ha demostrado una asombrosa capacidad de aprovechamiento creativo de redes sociales como Facebook, Instagram o Twitter. En concreto, Twitter se ha mostrado mucho más activa y proclive a la práctica y experimentación con las formas breves. Si bien la limitación de caracteres determina tecnológicamente la brevedad, esta no responde únicamente a una motivación exógena, sino que posee una rica tradición literaria a la espalda. Por ello, este artículo abordará el estudio de la tuiteratura en relación con su realidad mediática $\mathrm{y}$, también, con su inscripción genérica; asimismo, se hará hincapié en el «funcionamiento» de las formas breves en un entorno digital que nos obliga a revisar las posiciones auráticas e institucionales sobre el arte y la literatura. 
The online community has demonstrated an amazing capacity for creative use of social networks such as Facebook, Instagram or Twitter. Specifically, Twitter has been much more active and prone to practice and experimentation with brief literary forms. Although brevity is determined technologically by the limit of characters, this fact does not only respond to an exogenous motivation, but also there is a rich literary tradition behind it. Therefore, this paper will study the twitterature in relation to its media reality and, also, from its literary perspective; besides, I will focus on the "functioning" of digital literature to review the auratic and institutional positions on art and literature.

La communauté en ligne a démontré une capacité étonnante d'utilisation créative de réseaux sociaux tels que Facebook, Instagram ou Twitter. Plus précisément, Twitter a été plus actif et enclin à pratiquer et à expérimenter avec des formes brèves. Bien que la limitation des caractères détermine technologiquement la brièveté, elle ne répond pas seulement à une motivation exogène, mais s'appuie également sur une riche tradition littéraire. Cet article traitera donc de l'étude de la twittérature en relation avec sa réalité médiatique et avec la question des genres littéraires; de plus, l'accent sera mis sur le «fonctionnement» des formes brèves dans le cyberspace, qui nous oblige à revoir les positions des institutions sur l'art et la littérature.

\section{ÍNDICE}

Mots-clés: Twitter, twitterature, littérature numérique, formes brèves, littérature mexicaine, cyberculture

Palabras claves: Twitter, tuiteratura, literatura digital, formas breves, literatura mexicana, cibercultura

Keywords: Twitter, twitterature, digital literatura, brief forms, mexican literatura, cyberculture

\section{AUTOR}

\section{PAULO A. GATICA COTE}

Universidade de Santiago de Compostela 